\title{
Glioblastoma Treatment in the Elderly in the Temozolomide Therapy Era
}

\author{
Linda Coate, Mairéad G. McNamara, Zarnie Lwin, Derek MacFadden, \\ Ahmed Al-Zahrani, Christine Massey, Cynthia Menard, Barbara Ann Millar, \\ Arjun Sahgal, Normand Laperriere, Warren P. Mason
}

\begin{abstract}
Background: Optimal treatment of glioblastoma (GBM) in the elderly remains unclear. The impact of age on treatment planning, toxicity, and efficacy at a Canadian Cancer Centre was retrospectively reviewed. Methods: Glioblastoma patients treated consecutively between 2004 and 2008 were reviewed. Utilizing 70 years as the threshold for definition of an elderly patient, treatments and outcome were compared in younger and elderly populations. Results: Four hundred and twenty one patients were included in this analysis and median overall survival (OS) for the entire cohort was 9.8 months. 290 patients were aged <70 (median age 57, range 1769 ) and 131 were aged $\geq 70$ (median age 76 , range 70-93). Patients $\geq 70$ were more likely to receive best supportive care (BSC) and all patients $>70$ who were treated with radiotherapy received $<60$ Gy $(P<0.001)$, except one. Patients aged $>70$ demonstrated inferior survival (one year OS $16 \%$ versus $54 \%$ for those $<70$, HR $3.46, P<0.001$ ). In patients treated with BSC only, age had no impact on survival (median survival two months in both groups, HR $0.89, P=0.75)$. For those treated with higher doses of radiotherapy $(>30$ Gy to $<60 \mathrm{~Gy}$ ), one year survival was $19 \%$ versus $24 \%$ in patients aged $>70$ versus $<70$ (HR $1.47, P=0.02)$ respectively. Conclusion: In this retrospective single institution series, elderly patients were more likely to be treated with BSC or palliative doses of radiotherapy. Randomized phase III study results are required for guidance in treatment of this population of patients.
\end{abstract}

RÉSUMÉ: Traitement du glioblastome chez les gens âgés à l'ère du traitement par le témozolomide. Contexte : On ne connait pas vraiment quel est le traitement optimal du glioblastome (GBM) chez les gens âgés. L'impact de l'âge sur la planification du traitement, sa toxicité et son efficacité ont été revus rétrospectivement dans un Centre canadien de traitement du cancer. Méthode : Les dossiers des patients atteints de glioblastome, qui ont été traités de façon consécutive entre 2004 et 2008, ont été revus. Nous avons comparé le traitement et le résultat chez des patients plus jeunes et chez des patients âgés, en prenant 70 ans comme seuil pour déterminer si le patient était âgé. Résultats : Cette analyse porte sur 421 patients dont la survie médiane globale (SG) pour la cohorte entière était de 9,8 mois. Deux cent quatre-vingt-dix patients étaient âgés de moins de 70 ans (âge médian 57 ans, écart 17 à 69 ans) et 131 étaient âgés de 70 ans ou plus (âge médian 76 ans, écart 70 à 93 ans). Les patients de 70 ans ou plus étaient plus susceptibles de recevoir simplement les meilleurs soins d'appoint (MSA) et tous les patients de plus de 70 ans traités par radiothérapie ont reçu $<60$ Gy $(\mathrm{p}<0,001)$, sauf un. Les patients de plus de 70 ans ont eu une survie inférieure, seulement $16 \%$ versus $54 \%$ ayant eu une survie de 1 an (RR 3,$46 ; p<0,001)$. Chez les patients qui ont reçu seulement des soins d'appoint, l'âge n'avait pas d'impact sur la survie (survie médiane de 2 mois dans les deux groupes, RR 0,$89 ; p=0,75$ ). Chez ceux qui ont reçu des doses plus élevées de radiothérapie (> 30 Gy à < 60 Gy), la survie d'un an était de $19 \%$ versus $24 \%$ chez les patients âgés de plus de 70 ans versus ceux qui étaient âgés de moins de 70 ans (RR 1,47; p = 0,02) respectivement. Conclusion : Dans cette série rétrospective de cas traités dans la même institution, les patients âgés étaient plus susceptibles de recevoir des soins d'appoint seulement ou des doses palliatives de radiothérapie. Il faudra procéder à une étude randomisée de phase III pour préciser quel est le traitement à privilégier chez cette population de patients.

Can J Neurol Sci. 2014; 41: 357-362

Glioblastoma (GBM) is the most common primary brain tumor in adults ${ }^{1}$. Approximately $50 \%$ of cases of GBM occur in individuals who are 65 years or older ${ }^{2}$. A study of the surveillance, epidemiology and end results (SEER) registry database of patients diagnosed with cancer between 1973 and 2000 demonstrated an increase in the incidence of GBM with the fastest increase observed in elderly patients $(70 \text { years and older })^{3}$ and as the elderly segment of the population increases, the number of elderly patients diagnosed with GBM is expected to rise.

The optimal management of GBM in elderly patients, in terms of both efficacy and quality of life, is controversial due to the poorer prognosis, a perceived suboptimal response to and poor tolerance of radiotherapy and chemotherapy, and the higher frequency of comorbidities observed in the elderly population ${ }^{4}$.

From the Pencer Brain Tumour Centre (LC, MGM, ZL, DM, AA, WPM), Department of Biostatistics (CMa), Department of Radiation Oncology (CMe, BAM, AS, NL), Princess Margaret Cancer Centre, Toronto, Ontario, Canada; Mid-Western Regional Hospital Limerick (LC), Limerick, Ireland; Department of Medical Oncology (ZL), Royal Brisbane and Women's Hospital, University of Queensland, Brisbane, Australia; Department of Medical Oncology (AA), King Faisal Cancer Center, Riyadh, Saudi Arabia.

Received July 22, 2013. Final Revisions Submitted November 5, 2013 Correspondence to: Warren P. Mason, Pencer Brain Tumour Centre, Princess Margaret Cancer Centre, 610 University Avenue, Suite 18-717, Toronto, Ontario, M5G 2M9,

Canada. Email: warren.mason@uhn.ca. 
All these factors may account for the exclusion of elderly patients from clinical trials and thus explain the lack of evidencebased guidelines. Older age and poor performance status have been shown to be negative prognostic factors in $\mathrm{GBM}^{5,6}$ and despite treatment advances, to date, the survival of elderly GBM patients is usually less than 12 months ${ }^{7}$.

Following maximal feasible surgical resection, radiotherapy has been shown to improve overall survival in patients with GBM, and is offered to the majority of patients with this disease $^{8}$. Although, a radiotherapy dose of $60 \mathrm{~Gy}$ in 30 fractions is considered as optimal treatment, shorter courses at a lower dose are often offered to poor performance and elderly patients $7,9,10$.

The practice-transforming study by Stupp et $a l^{11}$ resulted in concurrent and adjuvant temozolomide combined with radiotherapy emerging as the standard of care for most patients with $\mathrm{GBM}^{12}$. However, patients older than 70 years were excluded from this study, therefore the suitability of this regimen for elderly GBM patients is unclear.

We performed a retrospective analysis of our ambulatory experience of consecutive elderly GBM patients who presented to Princess Margaret Cancer Centre to capture the treatments they received and how they benefited when compared to their younger counterparts.

\section{Materials AND Methods}

\section{Patients}

From January 2004 to July 2008, 517 consecutive newlydiagnosed patients with GBM were identified through the Cancer Care Ontario registry and those who received treatment at Princess Margaret Cancer Centre, Toronto were analyzed. Patients who were $<16$ years-of-age, those who were not newly diagnosed at the time of registration, were consulted at our institution for a second opinion only, did not have pathological confirmation of GBM or had GBM of the spinal cord were further excluded.

Data were retrospectively extracted from the electronic patient record by three investigators ( $\mathrm{ZL}, \mathrm{AAZ}$ and $\mathrm{DMcF})$. Of the 421 eligible patients, patient-related, tumour-related, and treatment related variables were extracted from the patients' records and entered into an electronic database. Data on patient demographics, Eastern Cooperative Oncology Group (ECOG) performance status, extent of surgery, treatments planned and delivered including combined modalities, radiotherapy dose, total number of adjuvant temozolomide cycles received, toxicity of all therapies and outcome were captured. Partial resection was defined as less than $90 \%$ tumor removal, subtotal resection was defined as less than $100 \%$ but greater than $90 \%$ tumor removal as per post-operative neurosurgical documentation. Treatment options included best supportive care (palliative care) only, aggressive treatment with 60 Gy radiotherapy concurrent with temozolomide +/- adjuvant temozolomide, palliative active treatment consisting of either palliative dose radiotherapy (30 Gy or less) or more aggressive palliative radiotherapy ( $>30$ Gy but less than $60 \mathrm{~Gy})$. We documented those treated with an abbreviated course of radiotherapy (40 Gy in 15 fractions over three weeks) as this dose had been adapted in our institution based on a previous prospective study by Roa et al in which no difference in survival was seen when compared to the standard
$60 \mathrm{~Gy}$ in 30 fractions over six weeks in post-operative GBM patients, age $>60$ years ${ }^{10}$. For our study, a threshold of 70 yearsof-age was deemed as the cut off to draw comparisons of all data. Overall survival was calculated from the time of diagnosis to death. Patients with incomplete follow-up were censored on the last date they were known to be alive. 0(6)-methylguanine DNA methyltransferase (MGMT) promoter methylation status was not available for patients as this was not routinely requested in the time period studied.

Adverse events were recorded utilizing the descriptions and grading scales found in the revised National Cancer Institute Common Terminology Criteria for Adverse events, version 4.0. Our study was approved by relevant institutional ethics review boards.

\section{Statistics}

Categorical variables were summarized using frequencies and percentages. Continuous variables were summarized using medians and ranges. Toxicities during treatment were analyzed using Fisher's exact test, the Cochran-Armitage trend test and logistic regression models.

Overall survival was measured from the date of diagnosis until the date of death. Patients alive at last follow-up were censored. Survival times were investigated using Kaplan-Meier plots, log-rank tests and Cox proportional hazards models.

Linearity assumptions in regression models were tested with quadratic terms. Proportional hazards assumptions were tested using phreg's assess statement and time-varying covariates.

Additional univariable associations were analyzed using Fisher's exact test and the row mean score test, as appropriate.

All analyses were generated using SAS software, Version 9.2 TS Level 2MO of the SAS System for Windows, copyright (C) 2002-2008 (SAS Institute Inc., Cary, NC, USA). Cases with missing values were excluded from all analyses. All $P$-values reported are two-sided and exact values are given where feasible.

\section{RESUlts \\ Patients}

In our study, 421 patients with newly-diagnosed GBM were identified for analyses. Of these, 290 were $<70$ years and 131 were $\geq 70$ years old at diagnosis. The median age at diagnosis for the entire cohort was 62 years (range 17-93 years). For patients aged less than 70 years, the median age at diagnosis was 57 years (range 17-69) and for patients aged 70 and older, the median age at diagnosis was 76 years (range 70-93). Elderly patients were more likely to have a worse performance status $(P<0.001)$, and were more likely to be female although this trend did not reach statistical significance (Table 1).

\section{Treatment}

Treatment data were available for all 421 eligible patients. In the younger group $(N=290)$ ( $<70$ years), 59 (21\%) had biopsy only, $180(62 \%)$ had partial resection and $51(17 \%)$ had subtotal resection. In the elderly cohort $(N=131)$ ( $\geq 70$ years), $52(40 \%)$ had biopsy only, $54(41 \%)$ had partial resection and $25(19 \%)$ had subtotal resection. The elderly cohort ( $\geq 70$ years) was more likely to have treatment planning as either best supportive care (palliative care), or purely palliative treatment (radiotherapy $\leq 30$ 
Table 1: Demographics for entire cohort of patients $(N=421)$

\begin{tabular}{|c|c|c|c|c|c|c|c|c|}
\hline \multirow[b]{3}{*}{ Variable } & \multirow[b]{3}{*}{ Category } & \multirow{2}{*}{\multicolumn{2}{|c|}{$\begin{array}{c}\text { Total } \\
N=421 \\
100 \%\end{array}$}} & \multicolumn{4}{|c|}{ Age at Diagnosis } & \multirow[b]{3}{*}{$P$-value } \\
\hline & & & & \multicolumn{2}{|c|}{$\begin{array}{c}<70 \text { Years } \\
N=290 \\
68.9 \%\end{array}$} & \multicolumn{2}{|c|}{$\begin{array}{c}\geq 70 \text { Years } \\
N=131 \\
31.1 \%\end{array}$} & \\
\hline & & $\mathbf{N}$ & $\%$ & $\mathbf{N}$ & $\%$ & $\mathbf{N}$ & $\%$ & \\
\hline \multirow[t]{4}{*}{ Treatment Group } & Unknown & 2 & & 1 & & 1 & & \multirow[t]{4}{*}{$<0.001$} \\
\hline & ${ }^{\mathrm{a}}$ Aggressive & 204 & 48.7 & 203 & 70.2 & 1 & 0.8 & \\
\hline & ${ }^{\mathrm{b}}$ Palliative Active & 173 & 41.3 & 72 & 24.9 & 101 & 77.7 & \\
\hline & ${ }^{\mathrm{C}}$ Palliative Care & 42 & 10.0 & 14 & 4.8 & 28 & 21.5 & \\
\hline \multirow[t]{5}{*}{ Treatment Group } & Unknown & 2 & & 1 & & 1 & & \multirow[t]{5}{*}{$<0.001$} \\
\hline & Aggressive $\quad 60 \mathrm{~Gy}$ & 204 & 48.7 & 203 & 70.2 & 1 & 0.8 & \\
\hline & Palliative Active $\quad>30$ Gy but $<60$ Gy & 113 & 27.0 & 57 & 19.7 & 56 & 43.1 & \\
\hline & Palliative Active $\leq 30 \mathrm{~Gy}$ & 60 & 14.3 & 15 & 5.2 & 45 & 34.6 & \\
\hline & Palliative Care & 42 & 10.0 & 14 & 4.8 & 28 & 21.5 & \\
\hline \multirow[t]{2}{*}{ Gender } & Female & 157 & 37.3 & 101 & 34.8 & 56 & 42.7 & \multirow[t]{2}{*}{0.13} \\
\hline & Male & 264 & 62.7 & 189 & 65.2 & 75 & 57.3 & \\
\hline \multirow{6}{*}{$\begin{array}{l}{ }^{\mathrm{d}} \mathbf{E C O G} \\
\text { performance status }\end{array}$} & Unknown & 6 & & 5 & & 1 & & \multirow[t]{6}{*}{$<0.001$} \\
\hline & \begin{tabular}{|l|}
0 \\
\end{tabular} & 107 & 25.8 & 92 & 32.3 & 15 & 11.5 & \\
\hline & 1 & 169 & 40.7 & 122 & 42.8 & 47 & 36.2 & \\
\hline & 2 & 56 & 13.5 & 33 & 11.6 & 23 & 17.7 & \\
\hline & 3 & 58 & 14.0 & 26 & 9.1 & 32 & 24.6 & \\
\hline & 4 & 25 & 6.0 & 12 & 4.2 & 13 & 10.0 & \\
\hline
\end{tabular}

${ }^{a}$ Aggressive; concurrent radiotherapy 60 Gy with temozolomide +/- adjuvant temozolomide, ${ }^{b}$ Palliative Active; palliative dose radiotherapy ( $\leq 30 \mathrm{~Gy}$ ) or more aggressive palliative radiotherapy ( $>30 \mathrm{~Gy}$ but $<60 \mathrm{~Gy}$ ), ${ }^{\text {CPalliative }}$ Care; best supportive care, ${ }^{\mathrm{d} E C O G}$; Eastern Cooperative Oncology Group.

Gy or between 30 Gy and 60 Gy). When standard dose radiotherapy was planned, only one patient $\geq 70$ years received a dose of 60 Gy. This was a highly significant finding $(P<0.001)$ (Table 1).

A total of 377 patients received radiotherapy. In the entire cohort encompassing all age groups, the median radiotherapy dose was $60 \mathrm{~Gy}$. In the younger group ( $<70$ years), the median dose of radiotherapy was 60 Gy but in the elderly group $(\geq 70$ years), the median dose amongst those treated was $40 \mathrm{~Gy}$ $(P<0.001)$.

There were 204 patients who received concurrent and adjuvant temozolomide (203 were $<70$ years, one patient was $\geq 70$ years). Of these, 195 younger patients ( $<70$ years) $(96 \%)$ completed a median number of five cycles (range 1-20) of adjuvant temozolomide following concurrent chemoradiotherapy. Six elderly patients ( $\geq 70$ years) $(5 \%)$ received a median number of 2.5 cycles (range 1-6) of temozolomide immediately following single modality radiotherapy. At disease progression, 11 elderly patients ( $\geq 70$ years) $(8 \%)$ received a median of six cycles (range 1-8) of temozolomide. We documented 9 of these 11 patients had a performance status of $0-1$ at the time of disease progression and previously underwent either partial or subtotal GBM resection at diagnosis.

In the entire cohort, three patients ( $<70$ years) were enrolled in the phase I/II trial of concurrent everolimus with temozolomide/radiotherapy followed by adjuvant everolimus/ temozolomide in newly diagnosed glioblastoma ${ }^{13}$. Two patients ( $\geq 70$ years) were enrolled in the randomized phase III study of temozolomide and short-course radiotherapy versus short course radiotherapy alone in the treatment of newly diagnosed glioblastoma in elderly patients ${ }^{14}$.

\section{Survival}

Of the 421 patients, 328 had died by last follow-up. The median survival for the entire cohort was 9.8 months (2 days-5.2 years). Of the 290 younger patients, $79(27.2 \%)$ were still alive at last follow-up, with a median follow-up of 1.8 years (2 days5.3 years). Of the 131 elderly patients, 14 (10.7\%) were still alive at last follow-up with a median follow-up of 0.6 years $(9$ days-1.2 years). When we compared the entire cohort by age, there was a statistically significant reduction in survival in patients aged 70 years and older (median survival was 0.33 years) in contrast to patients younger than 70 years (median survival of 1.09 years) $(P<0.001)$ (Figure 1$)$.

When we investigated age-related differences in survival with respect to specific treatments there was no difference in those planned for palliative care only $(P=0.75)$ (Figure 2). Specifically, for patients who received palliative dose radiotherapy ( $\leq 30 \mathrm{~Gy}$ ), there was no significant difference in survival between younger ( $<70$ years) and elderly patients $\geq 70$ years. Furthermore, for those treated with more aggressive palliative radiotherapy regimens ( $>30 \mathrm{~Gy}$ but less than $60 \mathrm{~Gy}$ ), elderly patients had a one year survival of $19 \%$ compared to their younger counterparts $(24 \%)(P=0.02)$ (Figure 3$)$. As only one patient $\geq 70$ years received 60 Gy radiotherapy, survival comparisons based on age for conventional doses of radiotherapy was not possible. 


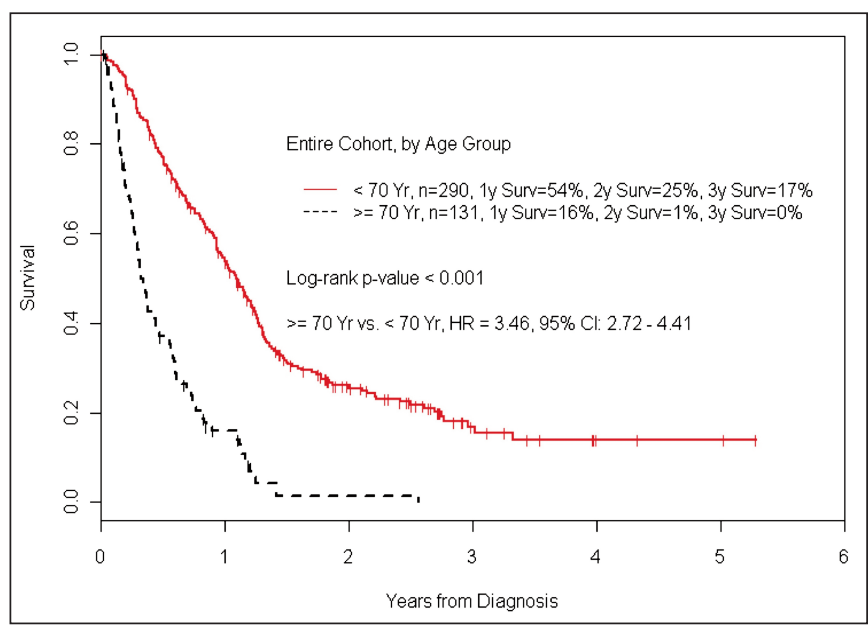

Figure 1: Survival by age in entire cohort of patients [unselected $(N=421)]$

In a multivariable analysis, factors affecting outcome were age, treatment and ECOG performance status. When age was included in the cox proportional hazards regression model and an interaction between age and treatment were included in the multivariable model, there was a significant interaction demonstrated between age at diagnosis and treatment effect $(P=0.006)$ (Table 2).

\section{Toxicity}

Sixty five patients $(22 \%)<70$ years experienced some toxicity on treatment, with $20(7 \%)$ experiencing thrombocytopenia and two of these patients having grade 3 thrombocytopenia. Fourteen patients $(5 \%)<70$ years had neutropenia, $9(3 \%)$ anaemia and $8(3 \%)$ fatigue. Nine patients $(7 \%) \geq 70$ years had toxicity recorded with three $(2 \%)$ having thrombocytopenia. No grade 4 adverse events were recorded.

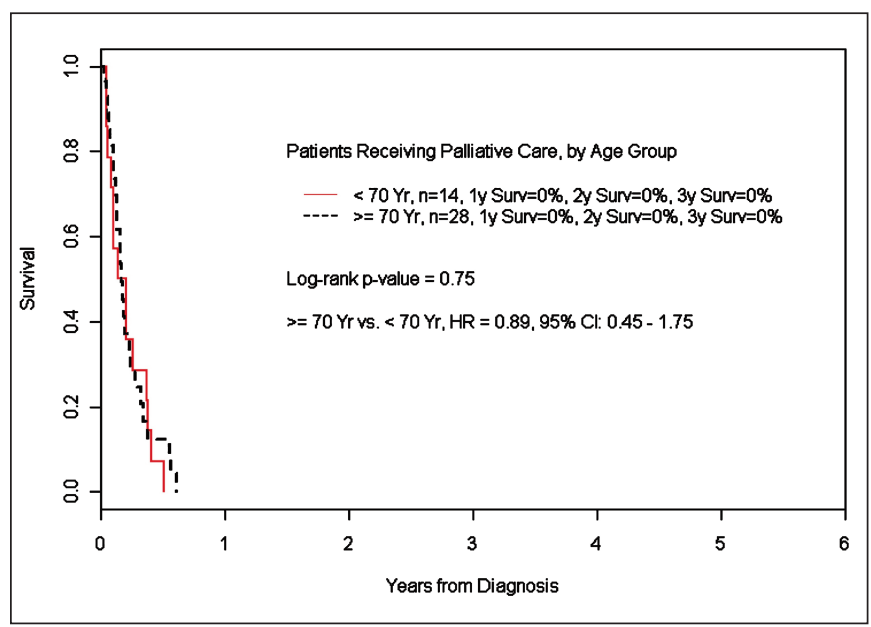

Figure 2: Survival by age in Palliative care group (best supportive care) $(N=42)$

There was no evidence of an association between age and increased toxicity in our analysis but this is likely due to fewer number of elderly patients receiving temozolomide. In the entire cohort, younger age and female sex were associated with increased toxicity $(P=0.002)$.

\section{Discussion}

In this retrospective analysis of a large ambulatory practice at Princess Margaret Cancer Centre, only one patient with a diagnosis of glioblastoma who was $\geq 70$ years was treated with radiotherapy at a dose of $60 \mathrm{~Gy}$. Our cohort time frame reflects the treatment era immediately following data published from the landmark European Organisation for Research and Treatment of Cancer-National Cancer Institute of Canada (EORTC-NCIC) study ${ }^{11}$, which had cemented the new standard of care in the treatment paradigm of newly diagnosed GBM. In our study,

Table 2: Univariable and multivariable analysis outcomes for Overall Survival

\begin{tabular}{|c|c|c|c|c|c|c|c|c|c|}
\hline \multirow{3}{*}{$\begin{array}{l}\text { Variable } \\
\text { Age at diagnosis }\end{array}$} & \multirow[b]{3}{*}{-} & \multicolumn{4}{|c|}{ Univariable analysis } & \multicolumn{4}{|c|}{ Multivariable analysis } \\
\hline & & \multirow{2}{*}{\begin{tabular}{r|}
${ }^{\mathbf{a}} \mathbf{H R}$ \\
1.8
\end{tabular}} & \multicolumn{2}{|c|}{\begin{tabular}{|c|}
$95 \%$ \\
Confidence \\
Interval (CI) \\
\end{tabular}} & \multirow{2}{*}{\begin{tabular}{|c|} 
Wald test \\
$\boldsymbol{P}$-value
\end{tabular}} & \multirow{2}{*}{\begin{tabular}{r|}
$\mathbf{H R}$ \\
1.3
\end{tabular}} & \multicolumn{2}{|c|}{$\begin{array}{c}95 \% \\
\text { Confidence } \\
\text { Interval (CI) }\end{array}$} & \multirow{2}{*}{$\begin{array}{c}\text { Wald test } \\
\boldsymbol{P} \text {-value } \\
<0.001\end{array}$} \\
\hline & & & 1.6 & 2.0 & & & 1.2 & 1.5 & \\
\hline \multirow[t]{2}{*}{ Treatment } & $\begin{array}{l}{ }^{b} \text { Palliative Active } \\
\text { vs. }{ }^{c} \text { Aggressive }\end{array}$ & 3.6 & 2.9 & 4.7 & $<0.001$ & 1.9 & 1.4 & 2.6 & $<0.001$ \\
\hline & $\begin{array}{l}{ }^{\mathrm{d}} \text { Palliative Care } \\
\text { vs. Aggressive }\end{array}$ & 17.7 & 11.8 & 26.7 & $<0.001$ & 7.0 & 4.0 & 12.0 & $<0.001$ \\
\hline Gender & Female vs. Male & 1.0 & 0.8 & 1.3 & 0.76 & 0.9 & 0.7 & 1.2 & 0.61 \\
\hline \multirow[t]{4}{*}{${ }^{\mathrm{e}} \mathrm{ECOG}$ performance status } & 1 vs. 0 & 1.7 & 1.3 & 2.3 & $<0.001$ & 1.4 & 1.0 & 1.9 & 0.03 \\
\hline & 2 vs. 0 & 4.7 & 3.3 & 6.9 & $<0.001$ & 3.3 & 2.3 & 4.9 & $<0.001$ \\
\hline & 3 vs. 0 & 7.5 & 5.1 & 10.9 & $<0.001$ & 3.2 & 2.1 & 4.9 & $<0.001$ \\
\hline & 4 vs. 0 & 8.8 & 5.5 & 14.3 & $<0.001$ & 2.4 & 1.4 & 4.2 & 0.002 \\
\hline
\end{tabular}

${ }^{\mathrm{a}} \mathrm{HR}$; Hazard Ratio, ${ }^{\mathrm{b}}$ Palliative Active; palliative dose radiotherapy $(\leq 30 \mathrm{~Gy})$ or more aggressive palliative radiotherapy ( $>30$ Gy but $<60 \mathrm{~Gy}$ ), ${ }^{\mathrm{c}}$ Aggressive; concurrent radiotherapy $60 \mathrm{~Gy}$ with temozolomide $+/$ - adjuvant temozolomide, ${ }^{\mathrm{d} P a l l i a t i v e ~ C a r e ; ~ b e s t ~ s u p p o r t i v e ~ c a r e, ~}{ }^{\mathrm{e}} \mathrm{ECOG}$; Eastern Cooperative Oncology Group. 


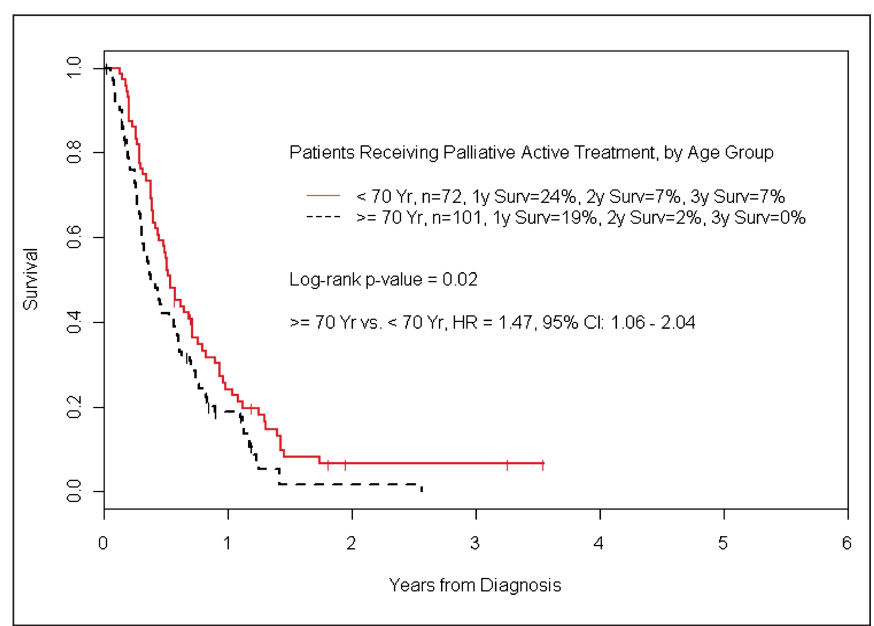

Figure 3: Survival by age in Palliative active treatment group (palliative dose radiotherapy [ $\leq 30 \mathrm{~Gy}$ ] or more aggressive palliative radiotherapy [>30 Gy but <60 Gy]) $(N=173)$

patients $\geq 70$ years with a diagnosis of GBM were more likely to receive best supportive care or palliative doses of radiotherapy. This is probably an appropriate decision, since at the current time there is no evidence to support radiotherapy treatment at $60 \mathrm{~Gy}$ in elderly patients, given that patients $\geq 70$ years were excluded from the original EORTC-NCIC study published in 2005. The five year follow-up analysis of this study did however include a subset analysis by age. In this subset, 170 patients (30\%) were aged between 61 and 70 years. In this elderly subset, median survival for those who received concurrent radiotherapy with temozolomide followed by adjuvant temozolomide was 10.9 months (range 8.9-14.9) compared to 11.8 months (range 10.412.7) for those who received radiotherapy alone ${ }^{12}$ and compared to 14.6 months (range 13.2-16.8) for the entire cohort inclusive of all age groups ${ }^{12}$.

Furthermore, in the Nordic Elderly phase III Trial of newly diagnosed elderly GBM patients ( $>70$ years $)^{15}$, survival was better with temozolomide alone $\left(200 \mathrm{mg} / \mathrm{m}^{2}\right.$ on days $1-5$ every 28 days for up to six cycles) or with hypofractionated radiotherapy (34 Gy) than with standard radiotherapy alone (60 Gy) (Hazard Ratio (HR) for temozolomide versus standard radiotherapy 0.35 [95\% confidence interval (CI) 0.21-0.56], $P<0.0001$; HR for hypofractionated versus standard radiotherapy 0.59 [95\% CI $0.37-0.93$ ],$P=0.02$ ). This study concluded that both temozolomide and/or hypofractionated radiotherapy should be considered as standard treatment options in elderly patients with glioblastoma.

A smaller prospective trial in 43 consecutive elderly patients with GBM treated with hypofractionated radiotherapy (30 Gy over two weeks) followed by up to 12 cycles of adjuvant temozolomide $\left(150-200 \mathrm{mg} / \mathrm{m}^{2}\right.$ for five days during each 28 day cycle) resulted in a median overall survival of 9.3 months in these elderly patients with GBM while maintaining a good quality of life ${ }^{16}$. Another earlier prospective study in 79 consecutive elderly patients ( $>65$ years) with glioblastoma who underwent surgery reported that overall survival was better in patients who received radiotherapy (59.44 Gy in 33 fractions) plus adjuvant temozolomide $\left(150 \mathrm{mg} / \mathrm{m}^{2}\right.$ for five days every 28 days (Group C) compared to patients receiving the same radiotherapy dose alone (Group A) (14.9 months versus 11.2 months, $P=0.002$ ), but there was no statistical differences found between Group A and those receiving the same radiotherapy plus adjuvant chemotherapy with procarbazine, lomustine, and vincristine (Group B) or between Groups B and $C^{17}$.

A median overall survival of 10.6 months was reported in a prospective trial of 32 consecutive elderly patients with glioblastoma who had surgery followed by standard radiotherapy at 60 Gy plus concomitant temozolomide at $75 \mathrm{mg} / \mathrm{m}^{2}$ per day followed by six cycles of adjuvant temozolomide (150-200 $\mathrm{mg} / \mathrm{m}^{2}$ for five days during each 28 day cycle $)^{18}$. A phase II study of short course radiotherapy (40 Gy in 15 fractions over three weeks) plus concomitant $\left(75 \mathrm{mg} / \mathrm{m}^{2}\right)$ and adjuvant temozolomide (150-200 mg/m² for five days during each 28 day cycle) in elderly patients ( $>/=70$ years) with glioblastoma, reported a median overall survival of 12.4 months, and a one year and two year overall survival rate of $58 \%$ and $20 \%$ respectively ${ }^{19}$.

The multi-centre randomized study group of Neuro-oncology working group (NOA-08) phase III trial reported that doseintensified temozolomide $\left(100 \mathrm{mg} / \mathrm{m}^{2}\right.$ in one week on/one week off schedule) alone was non-inferior to radiotherapy (54-60 Gy in 30 fractions) alone for patients with anaplastic astrocytoma or GBM aged $>60$ years and a Karnofsky performance score of 60 or higher. However, patients who received temozolomide in this trial had a higher risk of death compared to those who received radiotherapy (HR 1.24, 95\% CI 0.94-1.63) ${ }^{20}$. The NOA-08 study did report that MGMT promoter methylation status seemed to be a useful biomarker for outcomes by treatment and could aid decision-making in the elderly population in the future as MGMT promoter methylation was associated with longer overall survival than the unmethylated status (11.9 months [95\% CI 9.0 - not reached] vs. 8.2 months [95\% CI 7.0-10.0]) and event free survival was longer in patients with MGMT promoter methylation who received temozolomide than in those receiving radiotherapy alone (8.4 months, [95\% CI 5.5-11.7] versus 4.6 months [95\% CI 4.2-5.0]). The opposite was true for patients with no methylation of the MGMT promoter (3.3 months [95\% CI 3.0-3.5] versus 4.6 months [95\% CI 3.7-6.3]). Only one patient $\geq 70$ years in our study received concurrent radiotherapy with temozolomide and six elderly patients received temozolomide in the adjuvant setting and 11 elderly patients received temozolomide on progression of disease, therefore firm conclusions on the benefit of temozolomide in our elderly cohort cannot be made.

Although the treatments offered to elderly GBM patients have become more aggressive, survival gains to date are very modest at best. We await the results of the multi-institutional (NCIC Clinical Trials Group CE.6, EORTC, Trans-Tasman Radiation Oncology Group (TROG) and Japanese group) randomized phase III study of concurrent temozolomide, 75 $\mathrm{mg} / \mathrm{m}^{2}$ daily orally, with short course radiotherapy over three weeks followed by adjuvant temozolomide, versus short course radiotherapy alone in the treatment of newly diagnosed glioblastoma in elderly patients $>65$ years ${ }^{14}$. Results from this multi-institutional study should provide further guidance on the management of this special population. Methylation status of the MGMT promoter and quality of life data is also being collected 
in this study and should provide informed evidence for future therapy decisions.

In conclusion, maximal safe surgical resection should be offered to elderly patients where appropriate, with follow-up radiotherapy given at a safe dose if the patient has maintained a good performance status. Temozolomide alone could also be considered post surgery ${ }^{15,20}$. Temozolomide at standard dose $\mathrm{e}^{11,16,18,19}$ could also be considered either concurrently and/or in the adjuvant setting in selected good performance status patients and MGMT promoter methylation status may also guide treatment in the future.

\section{REFERENCES}

1. Wen PY, Kesari S. Malignant gliomas in adults. N Engl J Med. 2008;359(8):492-507.

2. Fisher JL, Schwartzbaum JA, Wrensch M, Wiemels JL. Epidemiology of brain tumors. Neurol Clin. 2007;25(4):867-90.

3. Hess KR, Broglio KR, Bondy ML. Adult glioma incidence trends in the United States, 1977-2000. Cancer. 2004;101(10):2293-9.

4. Sahebjam S, McNamara M, Mason WP. Management of glioblastoma in the elderly. Clin Adv Hematol Oncol. 2012;10 (6):379-86.

5. Buckner JC. Factors influencing survival in high-grade gliomas. Semin Oncol. 2003;30(6):10-14.

6. Scott JG, Bauchet L, Fraum TJ, et al. Recursive partitioning analysis of prognostic factors for glioblastoma patients aged 70 years or older. Cancer. 2012;118(22):5595-600.

7. Keime-Guibert F, Chinot O, Taillandier L, et al. Radiotherapy for glioblastoma in the elderly. N Engl J Med. 2007;356(15): 1527-35.

8. Walker MD, Alexander E Jr, Hunt WE, et al. Evaluation of BCNU and/or radiotherapy in the treatment of anaplastic gliomas. A cooperative clinical trial. J Neurosurg. 1978;49(3):333-43.

9. Lutterbach J, Ostertag $\mathrm{C}$. What is the appropriate radiotherapy protocol for older patients with newly diagnosed glioblastoma? J Clin Oncol. 2005;23(12):2869-70.

10. Roa W, Brasher PM, Bauman G, et al. Abbreviated course of radiation therapy in older patients with glioblastoma multiforme: a prospective randomized clinical trial. J Clin Oncol. 2004;22 (9):1583-8.
11. Stupp R, Mason WP, van den Bent MJ, et al. Radiotherapy plus concomitant and adjuvant temozolomide for glioblastoma. $\mathrm{N}$ Engl J Med. 2005;352(10):987-96.

12. Stupp R, Hegi ME, Mason WP, et al. Effects of radiotherapy with concomitant and adjuvant temozolomide versus radiotherapy alone on survival in glioblastoma in a randomised phase III study: 5-year analysis of the EORTC-NCIC trial. Lancet Oncol. 2009;10(5):459-66.

13. National Institutes of Health webpage. Everolimus, temozolomide, and radiation therapy in treating patients with newly diagnosed glioblastoma multiforme (RTOG 0913). [updated 2013 Oct 3; cited 2013 Nov 1]. Available from: www.ClinicalTrials.gov Identifier: NCT01062399.

14. National Institutes of Health webpage. Radiation therapy with or without temozolomide in treating older patients with newly diagnosed glioblastoma multiforme. [updated 2013 May 22; cited 2013 Nov 1]. Available from: www.ClinicalTrials.gov Identifier: NCT00482677.

15. Malmstrom A, Gronberg BH, Marosi C, et al. Temozolomide versus standard 6-week radiotherapy versus hypofractionated radiotherapy in patients older than 60 years with glioblastoma: the Nordic randomised, phase 3 trial. Lancet Oncol. 2012;13(9): 916-26.

16. Minniti G, De Sanctis V, Muni R, et al. Hypofractionated radiotherapy followed by adjuvant chemotherapy with temozolomide in elderly patients with glioblastoma. J Neurooncol. 2009;91(1):95-100.

17. Brandes AA, Vastola $F$, Basso $U$, et al. A prospective study on glioblastoma in the elderly. Cancer. 2003;97(3):657-62.

18. Minniti G, De Sanctis V, Muni R, et al. Radiotherapy plus concomitant and adjuvant temozolomide for glioblastoma in elderly patients. J Neurooncol. 2008;88(1):97-103.

19. Minniti G, Lanzetta G, Scaringi C, et al. Phase II study of shortcourse radiotherapy plus concomitant and adjuvant temozolomide in elderly patients with glioblastoma. Int J Radiat Oncol Biol Phys. 2012;83(1):93-9.

20. Wick W, Platten M, Meisner C, et al. Temozolomide chemotherapy alone versus radiotherapy alone for malignant astrocytoma in the elderly: the NOA-08 randomised, phase 3 trial. Lancet Oncol. 2012;13(7):707-15. 